\title{
3-hydroxyisobutyric aciduria
}

INSERM

\section{Source}

INSERM. (1999). Orphanet: an online rare disease and orphan drug data base. $\underline{3-}$ hydroxyisobutyric aciduria. ORPHA:939

3 hydroxyisobutyric aciduria is characterised by ketoacidotic episodes, cerebral anomalies and facial dysmorphism. It is an org anic aciduria that involves valine metabolism. Thirteen cases have been described in the literature so far. Transmission is thought to be autosomal recessive. 